\title{
Пексическая база данных по чадским языкам и некоторые проблемы, связанные с заимствованиями
}

\begin{abstract}
Бесписьменные чадские языки Нигерии и Камеруна образуют самую большую ветвь семито-хамитской (афразийской) макросемьи. На протяжении нескольких тысячелетий носители чадских языков контактируют с народами, говорящими на нило-сахарских и нигеро-конголезских языках. Это нашло отражение, в частности, в многочисленных лексических заимствованиях. Поскольку носители чадских языков никогда не были доминантной силой в этом регионе, они всегда считаются заимствующей стороной, а донором - один из языков с более высоким социальным статусом: канури, багирми, фульфульде. В статье рассматриваются наиболее типичные ошибки, возникающие при таком подходе к контактной лексике. Для получения более достоверных результатов представляется необходимым подтвердить отсутствие этимологии у потенциального заимствования и представить таковую для слова в языке-доноре. Таким образом, исследования по исторической фонетике и создание баз данных должны предшествовать анализу лексических заимствований.
\end{abstract}

Ключевые слова: чадские языки, Африка, нило-сахарские языки, языки нигер-конго, этимология, заимствования, лексика, фонетика.

Основная цель создания «Дексической базы данных по чадским языкам» - представить как можно больший объем чадской лексики в виде этимологических статей с полной реконструкцией начального согласного и постепенным уточнением реконструкции интервокального (в первое время - основываясь на уже имеющихся работах по этой теме). Такая база данных позволяет уже сейчас полноценно использовать чадскую лексику в работах сравнительного характера, а не ограничиваться фрагментарным материалом, который допускает различную фонетическую интерпретацию. Дело в том, что практически все чадские языки сократили исходную фонетическую систему (за счет эмфатических, ларингальных, латеральных или иных фонем). Кроме того, только проанализировав полную базу данных, можно быть уверенным в регулярности рефлексов². Даже такая мелочь, как унификация фонетической записи, оказалась также весьма полезной и своевременной

Еще одно из направлений исследований, для которых важна полнота лексического материала - анализ контактной лексики. Эта проблема более чем актуальна для чадских языков, которые «на протяжении последних 4-6 тысяч лет подвергались влиянию со стороны языков нигер-конго, нило-сахарских и арабского, что привело к высокому уровню взаимного проникновения на разных уровнях» [JgIb I: XII]. По мнению авторов, в

\footnotetext{
1 Чадская ветвь семито-хамитской (афразийской) семьи включает в себя около 150 языков Нигерии и Камеруна.

2 Пока что чадские этимологии обычно сопровождаются комментарием 'reflex $x$ is possible' или 'I observed both $x$ and $y$ '.

${ }^{3}$ Использование разных систем обозначения (например, палатальная аффриката может передаваться как $t y, c, \breve{c})$ порождает путаницу в соответствиях и приводит к ложным этимологиям.
}

Journal of Language Relationship • Вопросы языкового родства • 7 (2012) • Рp. 105-117 • ㄷ Столбова О. В., 2012 
результате внешнего воздействия «большинство чадских языков в их современном виде с первого взгляда вряд ли можно отличить от соседних неродственных языков» [указ. соч.: XIII]. Такой пессимистический вывод кажется не вполне обоснованным. Именно с первого взгляда - по ключевым словам - можно определить принадлежность языка к чадской семье. В этот список входят такие корни, как * $m V t$ - 'умереть', *sVm- 'имя', * $l V s V-m$ 'язык', *t-sVn- 'нос', * $t V r$ - 'луна', * $k V r V p$ - 'рыба', “s $V$ 'пить', $t V$ 'есть (мягкую пищу)', * $\hat{s} V r$ 'корень', *sVn- 'Знать', местоимения 1-2-го лица ед. ч. $(n V, k V)$, числительные *kVn-d'три', ‘fVd-d- 'четыре' и нек. др. Значительная часть этого списка сохранилась в большинстве чадских языков, и почти все они имеют надежную семито-хамитскую этимологию. К сожалению, существенная часть словарного запаса в чадских языках, действительно, вытеснена заимствованиями. Наиболее частотны (особенно в восточной ветви) заимствования из арабского языка. Они, как и заимствования из европейских языков, легко идентифицируются, помечаются в словарях, классифицируются (об арабизмах в хауса см., например, [Baldi 1995]). Начиная с середины прошлого века [Greenberg 1947], исследуются заимствования в единственный хорошо изученный чадский язык - хауса ${ }^{4}$, а также хаусанские заимствования в канури (более подробно см. ниже). Подобные исследования на материале остальных чадских языков ведутся бессистемно и без использования какой бы то ни было методики. При определении направления заимствования чадским языкам заранее отводится роль заимствующей стороны. Приведем несколько примеров, демонстрирующих предвзятое отношение к этой проблеме.

1. В западной и центральной ветвях чадской семьи широко представлены рефлексы семито-хамитского корня “mr2 'масло, жир': 3.-чад. 3. нгамо, болева mor; 7. кулере mа̀ 'масло'; ц.-чад. 1. тера mar, 4. бата таaré 'жир', гуде má́rá 'масло'; 7а. сакун mir 'масло' и т. д.) 5 . Этот корень засвидетельствован в семитских языках (аккадский танй 'жир', древне-еврейский $m r$ 'откармливаться, становиться жирным; sich mästern', угаритский $m r$ ? 'стать жирным') и в агавской гр. кушитской семьи (оромо, арборе тоога 'жир')6. Помимо этого, в языках группы сура (зап.-ч. 2) представлены рефлексы сем.-хам. * $m r h$ 'смазывать маслом, масло’ (магхавул, мупун mwј̀r, гоемай mwiir, монтол mәуі (< *mәуir, метатеза) 'масло'). Кроме арабской параллели mrh [-а-] 'смазывать маслом’ [ВК: 1088], заслуживает внимания и египетское mrh.t (Др. ц.) ‘жир' [EG: 111]. Несмотря на очевидную сем.-хам. параллель и даже ссылку на нее, рефлексы * $m V H V r$ трактуются в [JgIb I: 63 'fat'] как несомненное заимствование из языков бамилеке (семья Нигер-Конго), а рефлексы ${ }^{*} m r-$ как возможное заимствование. [указ соч.: 130 mààr, mbūr 'масло']. Идее о заимствовании противоречат не только семитская параллель, но и более чем странные рефлексы внутри такой небольшой группы языков, как бамилеке. Дело в том, что прабамилеке *gbat 'жир' практически во всех языках отражается как m-vat, mà-gwút, mè-vét и т.п. [Williamson 1973: 150-3]. Исключением являются рефлексы в языках мама (тuru) и вуркум (тuruү). В отсутствии всякого объяснения такого фонетического развития внутри бамилеке (особенно, перехода * $g b$ - $>m-)$, вывод об обратном направлении заимствования: из семитохамитских языков в бамилеке напрашивается сам собой.

${ }^{4}$ Распространен в Северной Нигерии и прилегающих районах Нигера, а также в Камеруне, Дагомее, Гане и некоторых др. странах. Широко используется в Западной Африке как средство межэтнического общения, с XVI в. распространен в Западном и Центральном Судане как lingua franca. Общее число говорящих около 25-30 млн. чел, письменность с XVIII в.

${ }^{5}$ Краткие сведения о классификации чадских языков см. в конце статьи.

${ }^{6}$ Cм. [Kogan 2003]. 
2. B [Jglb I:1] отмечено, что канури kafa 'стрела' заимствовано в ц.-чад языки, а именно: ц.-чад. *xVf- 'стрела': 1. хона hafu-ra, гаанда həf-ta, габин xaf-ta, бока xaf-tə, тера fafa; 2. марги jàfú, fàfó, чибак xafə, килба hafa; 3. хиги нкафа, капсики, хиги база ха̀vо, фали гили хàvwu, фали кирия hàvà, банаа хàvà; 4. гуде ใàva, гуду áavù; 5. дгхведе, гава хаvà; 5а. хди hava; 7. чувок hàv. Между тем, соответствие согласных в анлауте достаточно странно для заимствования; оно опровергается другими примерами (в которых $k$ заимствуется как $k$ ), а чадский корень имеет параллель в геэзе: hера 'стрела' [LsG: 221].

3. О. Росслер предположил, что чадское слово 'рыба' - это заимствование, а источником его является ke-lop 'рыба' в языке темне (семья Нигер-Конго). Эта идея была поддержана и Г. Мукаровским ${ }^{7}$ Рефлексы чадского корня * $k V r V p$ - 'рыба' представлены во всех группах центральночадских языков, в большей части западных и (с ассимиляцией первого согласного) в одном восточном. Интервокальный -r- сохраняется в западных языках, в языках хиги и маса, но отражается как -l- в остальных центральночадских (т. е. дает регулярные рефлексы). Например, зап. 1. хауса kíifii (< $\left.{ }^{*} k i y f i<{ }^{*} k i r f i\right)^{8}$; 3. болева kerwo, нгамо kèrùfá, 5. богхом kiip, kirip, 7. кулере kirif; ц.-чад. 2. бура kilfa; 3. фали кирия kàràpa, бана k(a)lìp̀̀, мн. ч. kàrpì ; 5. малгва kálfe, главда kílfà, 5а. хди kerfe, ламанг kilpi, 7. мбуко káléf, ульдем kālìf; 10. зиме kirfe?, маса kùluf, (ц. ветвь) [StD IV, № 282]. С другой стороны, как следует из реконструкции К. И. Позднякова для атлантических языков [Поздняков 1993: 140-1], параллель к темне ke-lop 'рыба' есть только в языке бага-коба (та же подгруппа) - ku-rup 'рыба'. Самое интересное, что это слово входит в класс деревьев, что странно для исконной лексемы, но типично для заимствования (класс деревьев имеет показатель $k V / k \varepsilon)$. Заметим, что источником соответствия: темне -l- бага-коба - $r$ - может быть любой из вибрантов.

Очевидно, что слово сомнительного происхождения, засвидетельствованное лишь в двух близкородственных атлантических языках (но не реконструируемое на более высоком уровне), никак не могло быть источником заимствования на уровне ветвей или даже отдельных групп чадских языков. Тем не менее, гипотеза О. Росслера была не просто поддержана чадологами, но для большей убедительности и сама чадская реконструкция была переделана из *krp в *klp [JgIb I: 67], в нарушение фонетических соответствий, установленных в той же монографии (ср. [указ. соч., I: XXVII-XXIX]).

Основные ошибки авторов очевидны: игнорируются внешние параллели чадского корня, не устанавливается этимология слова-донора. Последнее излишне только для арабизмов, но не вполне корректно даже при заимствовании из канури, фула, багирми в группы или отдельные чадские языки (хотя следует признать, что социальный статус этих языков выше, чем любого чадского, за исключением хауса). И уж совсем странно, что этимология заимствованного слова не устанавливается, даже если в роли донора выступает язык того же социального уровня. Тем более некорректным кажется тезис о том, что «прачадскими являются только корни, сохранившиеся во всех трех ветвях» [указ. соч. I: XVII]. Этот тезис (опровергаемый имеющимися семито-хамитскими этимологями $\left.{ }^{9}\right)$ позволяет рассматривать как заимствования значительную часть чадских корней. Так же произвольно трактуется и фонетика заимствований. В приведенных выше примерах kafa заимствуется как xafa, 2àva; kelop - как kerwi, kàràpə и т. п. Между тем, свидетельством за-

\footnotetext{
7 [Jglb I:67].

${ }^{8}$ Из хауса это слово заимствовано в северные диалекты сонгай (тасавак kiifi и др. [Rueck 2001: 16]).

${ }^{9}$ В том числе и содержащимися в [JgIb], см., например зап.-вост. чад. * $\mathrm{SVn}$ ‘брат’ и др.-егип. параллель sn 'брат' на стр. 21.
} 
имствования всегда считалось фонетическое и семантическое тождество лексемы со словом-донором. Последнее положение подтверждается, например, в следующем случае:

4. Ц.-чад. 3. бана gàw, мн. ч. gàwêr 'охотник', 6. даба gàw 'охотник'; 7. гисига gaw 'охотник', ульдем gáw 'охотник' (заимствование из фула')10, мофу gáw (очень распространенное заимствование) 'охотник'; 9. мбара gáw 'охотник'; 10. маса gàw ‘индивидуальная охота’; в.-чад. 3. тумак gáw ‘охотник'. Это слово есть и в канури (gau 'охотник’), и в фула (gaw 'охотиться'). И, как и в чадских языках, это тоже заимствование. Источником заимствования является зарма (диал. сонгай) gaw 'охотник', gaway 'охота'11. По свидетельству Г. Турно, «слово gaw повсеместно представлено в ц.-чад. языках, без каких бы то ни было фонетических изменений. Gaw - это самоназвание особого племени или клана (Gao или Gow). В колониальной литературе есть публикации на тему «Les Gow ou chasseurs du Niger». В словаре сонгай есть еще и gow 'колдун (из касты охотников)'12. В этом значении слово попало в гр. котоко: логоне gaw 'колдун', gaw-sin 'магия'; макари gaw 'колдун, лекарь».

Можно предположить, что фонетический облик заимствованного слова не изменился, поскольку структура $\mathrm{CaC}$, с одной стороны, устойчива в чадских языках, с другой нетипична для них. Двусложное имя в чадских языках обычно имеет вид $C V C V$, и как раз второй гласный и провоцирует изменение фонетического облика, вызывая регрессивную ассимиляцию первого гласного и/или палатализацию /лабиализацию согласного. Гласный -a- первого слога нейтрален, поэтому структура и не изменилась.

5. К этому же типу заимствований относится следущий случай: 3.-чад. 3. карекаре gàbàga 'белая хлопчатобумажная ткань', 6. нгизим gàbàgá, мн. ч. gàbàgàgín 'узкая полоса ткани, из которой делают одежду', баде gabaga 'узкая полоса белой хлопчатобумажной ткани': ц.- чад. 2. бура gabaka 'тонкая ткань'; 7. муянг gàbàgà 'повязка, закрывающая глаза трупа', мофу gàbàga 'узкая полоса белой ткани'; 9. музгу gábaga 'полосы хлопчатобумажной ткани', мунжук gabaga 'полоса хлопчатобумажной ткани'. Структура gabaga абсолютно нехарактерна для чадских языков: при трех смычных согласных имя должно быть производным: *ga-baga или *gaba-ga. Однако ни подходящей первичной основы, ни аффикса ga в чадских языках нет. С другой стороны, заимствованное слово содержит три нейтральных гласных -a-, поэтому оно достаточно устойчиво и сохраняет исходную форму.

6. Противоположный пример - это арабское faras- 'лошадь'13, заимствованное в большинство чадских языков: ц.-чад. 5. зул pirsi, польчи pársá, двот parsi и т. д., ц.-чад. 1. тера pórsí, габин pirse и т. д.), 5. вандала pólša, дхведе plíši, главда páliša, 5а. ламанг pálísí, 7. мофу pálès, гисига poleš, зулго piris, мбуко poles и т. д.; 9а. гидар pársa; 9. музгу plis, в.-чад. 7. муби fírsó, масмадже farso, джегу pèsó и т. д. Фонетическая структура заимствования является наиболее частотной для чадских языков: в непроизводных корнях вида CVCVC- в позиции $C_{2}$ преобладают плавные. Очевидно, именно по причине ‘адаптированности’ и произошел переход *-r- >-l- (ровно в тех группах, где он отмечен для исконной лексики, ср. рефлексы * $k V r V p$ - 'рыба'). Гласный -i- второго слога в чадских языках указывает на

\footnotetext{
${ }^{10}$ Пометы о заимствовании даются в словарях.

11 [Zarma 2001: 8].

${ }^{12}$ Сообщение по электронной почте от 7.11.2011.

13 «И имя, и объект появились в Судане с приходом арабов, примерно в 1000 A.D.» [JgIb I: 95].
} 
возможность заимствования из какого-то местного диалекта арабского языка или на контаминацию с fāris- 'всадник'.

Таким образом, можно предположить, что сохраняют свой исходный фонетический облик неадаптированные заимствования с устойчивой фонетической структурой. А вот фонетические изменения исконных и адаптированных заимствованных слов происходят по одним и тем же фонетическим законам.

Все приведенные выше примеры касаются 'массовых' заимствований (мнимых или подлинных). Их легче всего обнаружить как раз при составлении базы данных. Однако в современной практике выявления заимствований за отправную точку берется языкдонор и анализируется его влияние на конкретный чадский язык или пару родственных языков. Такое исследование изолированной лексики достаточно часто приводит к ошибочным выводам.

Кроме арабского, в роли 'донора' обычно рассматривается язык канури (сахарская гр. нило-сахарской семьи). По мнению Р. Шу, народ канури не менее 1000 лет был доминантной политической силой на территории современных штатов Борно и Йобе (Нигерия) и восточной части Нигера, что привело к многочисленных заимствованиям из канури в чадские языки этого ареала [Schuh 2003: 1]. Такой высокий статус канури позволяет трактовать как заимствования любые слова в чадских языках, имеющие сходство с лексикой канури, не обращаясь к нило-сахарской или чадской этимологии. В указанной работе детально исследуются заимствования из канури в западночадские языки баде и нгизим (гр. 6, в нее входит еще язык дувай). Для объяснения заимствований типа канури sawa 'друг' > нгизим sabu и под. Р. Шу применил метод внутренней реконструкции. Он показал, что в лексике канури, опубликованной в 1854 г. [Kölle 1854], губные и велярные смычные еще сохранялись, а именно [указ. соч.: 10]:

$\begin{array}{ll}\text { канури, } 1854 \text { г. } & \text { современный канури } \\ \text { soobaa 'друг' } & \text { sawa } \\ \text { dabuи 'пуп' } & \text { dawu } \\ \text { kugui 'цыпленок, курица' } & \text { kuwui }\end{array}$

Таким образом, лексика, заимствованная в чадские языки раньше середины XIX в., должна показывать в языке-доноре интервокальные велярные и лабиальные фонемы, утраченные в современном канури. По мнению Р. Шу, период наиболее интенсивных заимствований приходится на XVI-XVII вв. К сожалению, в дальнейшем тот же метод был применен автором недостаточно корректно: в отсутствии (или вопреки) данным С. Кёлле. А именно: любое слово языка канури вида $C V w V$ может быть источником заимствования для чадских лексем вида $C_{1} V C_{2} V$ (при $\left.C_{2}=b, p, f, k, g\right)^{14}$. Наличие слова в списке С. Кёлле необязательно, фонетическое тождество слова из списка с заимствованием - тоже необязательно. Точное совпадение семантики необязательно. Приведем некоторые примеры.

7. Канури dàwi ‘мотыга с длинной ручкой’ является, по, мнению Р. Шу [указ. соч., 14], источником следующих заимствований: баде dabi, мн. ч. dababai 'мотыга с короткой ручкой и перпендикулярным лезвием', дувай dabi, мн. ч. dabakčit 'мотыга с перпендикулярным (к рукоятке) лезвием', нгизим dabi, мн. ч. dababin 'мотыга с короткой ручкой и пер-

${ }^{14}$ Отметим, что уже этому утверждению противоречат канури kafa 'стрела' (пример 2) и fufu 'легкие' (12). 
пендикулярным лезвием, используется для рубки стеблей проса; мотыга с длинным лезвием, используется для разрушения глиняных построек'. В словаре С. Кёлле для концепта 'мотыга' находим только канури báanoo и káale [Kölle: 84]. В подобных случаях доказательством заимствования может служить сахарская этимология, особенно, если близкородственные языки сохранили смычные фонемы. В отсутствие таковой вопрос о заимствовании следует считать открытым.

8. Канури sawàr 'торговля' > нгизим saafàr, баде saapər 'торговля' [Schuh 2003: 8]. В словаре канури слово помечено как арабизм, а у С. Кёлле записано как sáabər. Следовательно, нужно еще доказать, что - $b$ - в заимствованиях может оглушаться. Заметим, что весь собранный чадский материал показывает озвончение смычных в интервокальной позиции.

9. Канури mowosà 'ножницы' > нгизим, баде makas. Канури, в свою очередь, заимствовано из арабского miqas-. Прямое заимствование из арабского в чадские языки (с последующей ассимиляцией гласных: miqas- > mikas-15 > makas) кажется более вероятным. Тем не менее, Р. Шу сопровождает эти примеры следующим комментарием: «мы можем признать, что в нгизим и баде отражено архаичное произношение заимствованных из канури слов» [указ соч.: 8].

10. Канури gawaа 'ткань из хлопка' > нгизим gàbàgá, мн. ч. gàbàgàgín, баде gabaga 'узкая полоса белой хлопчатобумажной ткани’ [указ соч.: 8]. Выше приведен полный материал (см. пример 5), позволяющий предположить, что семантикой слова-донора должна быть 'узкая полоса хлопчатобумажной ткани'. Кроме того, лениция -g- в канури отмечена лишь для kugui > kuwui. При ином окружении велярные сохраняются, см., например, ngaga 'ворона', kaga 'предок', yakkə 'три' т.д. Таким образом, у нас нет никаких доказательств того, что канури gawaa 'ткань из хлопка' восходит к *gabaga.

11. Канури kárwí ‘кожаное колодезное ведро’ > нгизим kúrpî, баде karpi, мн. ч. kàrpan ‘колодезное ведро’ [указ. соч.: 14]. У того же автора (в более ранней публикации) находим: нгизим kúrpî < канури kárbí [Schuh 1981: 99] ${ }^{16}$. Прямое заимствование kúrpî < kárbí не выглядит убедительным, тем более, что канури kárbí заимствовано из арабского kirb-at'grande outre à lait ou à eau faite d'une seule peau cousue au milieu', т. е. 'большой бурдюк для молока или воды, сделанный из целой шкуры’ [ВК: 704]. Очевидными заимствованиями, возможно, непосредственно из арабского языка, являются: ц-чад. 5 малгва kә̀rbí ‘кожаный мешок для воды’ и 3.-чад. 6 дувай karbi ‘колодезное ведро’ (компенсаторная глоттализация звонкого: *krb > krb). Несколько параллелей к арабскому корню находим в

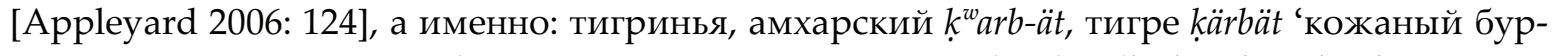
дюк', агавские: хамир qürbi, хамта qürvòi, квара, кемант $k^{w}$ ärbäy 'hide, skin, leather, кожа, шкура'. Еще одна кушитская параллель - бедауе kurbe 'шкура, кожа' [Reinisch 1895: 295]. Та же семантика отмечена в ц.-чад. языках (8. макари karabi 'шкура животного', karabi sí nse 'веко' (при si 'глаз'), 7а. сакун karabi 'козья/овечья шкура') и в канури (karáwi 'шкура, кожа'). Весь пока что собранный материал достаточно проблематичен. Агавская лексика дается без реконструкции, поскольку соответствие начальных согласных нерегулярно [см. указ. соч.: 15]. Это может свидетельствовать о заимствовании из эфио-семитских

15 Чад. * $k$ и * $k>k$ в гр. нгизим.

${ }^{16}$ С. Алисон [AlM: 5] ссылается на канури kárbí ‘sack for drawing water, колодезный мешок’ (по С. Кёлле). 
языков (которые, в свою очередь, могли заимствовать это слово из арабского). Семитский * $k$ регулярно соответствует $k$ в макари, поэтому нельзя говорить об общем источнике у семитского и чадского корней со значением 'шкура, кожа'. Заимствование из канури возможно, но у последнего нет никакой этимологии. Существует другое объяснение, а именно:- $k r-b$ 'шкура, кожа' в ц.-чад. языках - это одно из производных от двухсогласной ячейки $k-r$ 'кожа', с неэмфатическим велярным в начальной позиции. Суффикс - $b$ - как маркер живых существ отмечен в чадских языках и может иметь общее происхождение с суффиксом вредных животных (-b-) в семитских языках. Основа представлена следующими рефлексами:

а) *kVr- 'кожа': з.-чад. 4. паа kurri ‘кожа, skin’17, 5. богхом, кир kwaar, мангас kwar, тала kuur, були kur, геджи kúul, заар kúr, гуус kuиr 'кожа, skin', дотт kúr 'кожа, leather'; ц.-чад. 7.мерей kìri ‘кожа (человека)'; в.-чад. 3. сомрай gàré, ндам gāré18 ‘кожа’ [StD IV № 270]. Отметим еще одну нило-сахарскую 'параллель': зарма kuиru [Zarma 2001: 23], сев. диалекты сонгай ku:'ru [Rueck: 14] 'кожа, skin'.

b) Изделия из кожи: з.-чад. 3. дера kárá-kárá 'одежда из кожи животного', тангале kardè 'фартук из мягкой кожи, чтобы носить на спине ребенка'; ц.-чад. 'выделанная кожа': 5. подоко kíra-méte, 7. ульдем kùr-mètè.

c) Производный глагол 'снимать кожу': з.-чад 5. гуус kursa 'снимать кожу, кожуру', ц.-чад. 5а. хди kurtay 'снимать кожу'; 7. мофу -kúrt- 'снимать кожу, одежду'.

d) 'Кожаный щит': ц.-чад. 4. гуде kә̀rд̀má ‘большой кожаный щит’; в.-чад. 6. мокилко kòrkó 'щит (кожаный)'.

е) *kVr-p- ‘бич, хлыст’: з.-чад. 1. хауса kúrfóo ‘бич’; 6. дувай kúrpòk ‘бич, хлыст’; ц.-чад. 2. бура kurри 'бич’, 4. гуде kúráрà ‘бич из невыделанной кожи'; 5. главда kúrрà 'палка, бич’, 7. ульдем kúrpì ‘бич без рукоятки, хлыст’, 9. мунжук kurup 'бич из шкуры животного’. Похожая лексика есть в нило-сахарских языках: канури kárwo ‘бич’ и багирми kaurfo ‘бич’ [SkH: 154].

Никаких семито-хамитских параллелей к * $k V r$ - пока не обнаружено. Однако и канури не может рассматриваться как язык-донор - в нем есть только потенциальные заимствования из арабского и чадских языков. Серьезная проблема может возникнуть только при наличии у сонгай 'кожа' (11a) нило-сахарской этимологии с подходящей фонетической структурой.

Еще одним примером того, что пренебрежение полными чадскими данными приводит к ошибочным выводам, является список заимствований из канури в ц.-чад. язык макари (8 гр.) [AlM]. Приведем несколько наиболее явных примеров.

12. Канури kaga > макари kaka 'предок'19 [указ. соч.: 4]. При наличии чадской этимологии и кушитских параллелей (см. ниже) заимствование из чадского языка в канури должно быть как-то обосновано, тем более, что канури kaga в других публикациях считается заимствованием из хауса.

Чад. “ka(ka) 'дед, предок’: з.-чад. 1. хауса kàakaa 'родители, предки'; 3. карекаре kàaka ‘дед, предок’, дера káa 'дед’, тангалее kaagâ 'прадед, дед, бабка', перо gáagà ‘бабка’; 4 . мия kàaká 'дед’; 6. баде kàkau 'бабка', kàká 'дед’ (< канури kàgá), kàaka 'Бог', дувай kàakà 'дед’, 7. дафо káy, фьер kaá 'бабка', кулере kak- 'дед, бабка'; ц.-чад. 2. бура kaka 'предок, внук', 4. бана kх⿱亠 (<kaka) ‘бабка’; гуде kàká-nə ‘бабка’; 8. макари kaka 'предок’, kakari ‘пра-прадед’;

\footnotetext{
${ }^{17} k$ только из чад. * $k-$, чад. * $k>k$.

${ }_{18}$ В языках этой группы $g$ - < чад. * $k$ - и ${ }^{*} g-, k$ - < чад. * $k$.

19 Для всех чадских языков типично озвончение смычных в интервокальной позиции.
} 
в.-чад. 5. мигама kàakâ 'прапрадед, предок', 7. торам go-kok 'предок', koko 'бабка' [StD IV №28]. Вост.-куш. *2akk- ‘бабка, дед’ [Sasse 1978: 21], ю.-куш. бурунге koko ‘дед’.

13. Канури fufu 'легкие' > макари kofo [указ соч.: 5]. Кроме странного фонетического соответствия, идея о заимствовании опровергается чадскими данными: 3.-чад. 1. хауса kùufuu, kùuhuu; 4. паа kufi, дири akufu, цагу kïfan 'легкие'; 6. баде kúva 'грудь, легкие'; ц.-чад. * $g$-guf- (< *k-gVf-<*k-kVf-, где $k$ - - префикс частей тела) 'легкие’: 2. килба gúgùví, гр. хиги *guguf-, гр. бата *gùgùf- [StD IV №49].

14. Канури ngagд 'ворона' > макари haga 'ворона' [указ. соч.: 8]. Еще один пример странного соотношения согласных и игнорирования абсолютно надежной чадской параллели, а именно: ' fagak-/*gayak-/*'rak- 'ворона, ворон': 3.-чад. 2. гоемай ngak 'ворона', 5. зар

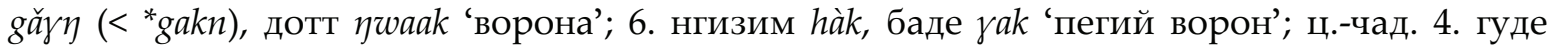
jàaká; 6. даба gáak (< ‘gáhák), 7. зулго Đgaák, мбуко ngàhák, гисига mu-jak, мофу mán-gàhák, 8. логоне nүakiz, макари hàgá 'ворона', мазера fàłákè 'сорока, corbeau-рie'; в.-чад. 7. муби gāk 'ворон', 4. мава gak ворона. Явно звукоподражательное слово, возможно, связано с араб-

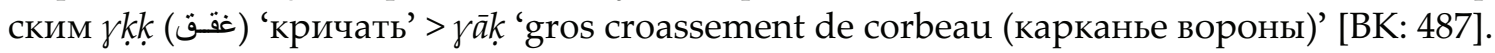

Возможно, что с канури ngaga как-то связан другой чадский корень с той же семантикой, однако без (нило)-сахарской этимологии выводы будут преждевременны:

15. * $g V g V$ 'ворона': з.-чад. 4. паа gaaga 'пегий ворон'; ц.-чад. 8. будума ngagé 'ворона'; в.-чад. 4. сокоро gā, 6. мокилко gàagú 'ворона'; 5. бидия gaaga 'сорока, corbeau-рie'. При всей проблематичности реконструкции любых звукоподражательных корней, 14 и 15 различаются и структурой, и рефлексом велярного согласного, а ${ }^{*} g g V$ могло изначально обозначать какую-то похожую птицу. Кроме того, есть и семитская параллель: геез $g u g \bar{a}, g^{w}$ əga 'сова, ночной коршун, ворон', тигре $g^{w} \partial g g^{w} a$, амхарский $g^{w} \ddot{a} g g a$ 'сова' (помечено как «ономатопоэтическое»). Из эфио-семитских языков слово попало в кушитские: оромо gugaa, сахо-афар guиgga, беджа guug [LsG: 184].

16. Канури gàrú 'городская стена' > макари karu 'комната' [AlM: 6]. Не вдаваясь в обсуждение этого маловероятного (по фонетическим причинам) заимствования, отметим, что следующая лексика также считается заимствованной из канури: 3.-чад. 1. хауса gàar̃úu, мн. ч. gáar̃úkà 'стена (города, компаунда, дома)'; 3. болева gàarú 'стена вокруг компаунда', дера gáarú 'городская стена', тангале kar, gar 'городская стена', 4. паа gáru 'каменная стена', 6. баде gaаru 'стена', нгизим gàarú 'любая глиняная стена', ц.-чад. 1. тера gàruk 'стена (вокруг города)', 5. малгва gàrú 'стена'. Доказательство заимствования из канури следующее: для исконных слов языка хауса в интервокальной позиции характерен ретрофлексный аллофон -r-, а вибрант (как в данном случае) характерен как раз для заимствований [AL: 46] $]^{20}$. Против заимствования есть несколько аргументов: долгий гласный и производное gárgárí ‘низкая стена' (с ретрофлексным -r-) в хауса, разнообразие семантики и разные тональные контуры слова в других чадских языках ${ }^{21}$ и внешние параллели, а именно: аккадское Zigāru, арамейский (ег. диал.) $2 g r$ 'стена', берберское нефуса a-grur 'ограда, стена', ахаггар a-gror 'ограда', кушитский оромо goorroo 'стена', иракв gârzai 'стена веранды' [StD IV №685].

20 Заметим, что рефлексы во всех остальных языках считаются заимствованиями из канури (без всяких объяснений).

${ }^{21}$ Пожалуй, только малгва garú 'стена' представляет собой прямое заимствование из канури. 
Кроме того, разумеется, при определении направления заимствования не был проанализирован представленный ниже чадский материал и его семито-хамитские параллели:

а) *gVr- 'ограда': з.-чад. 3. болева gargar, нгамо gàrgàr 'колючая изгородь', 6. дувай, баде gàrgàri id., 5. гурунтум, джими gàrni 'ограда', ц.-чад. 2. бура gar 'обнести оградой', 7. муянг gārgāá 'ограда, загон', 9. мбара gúrù 'загон'. Родственный корень представлен в куш. языках, гр. варази: *geer- 'ограда'.

b) *gVr- 'дом, амбар': 3.-чад. 3. болева gàare 'амбар', ц.-чад. 7. ульдем gèrgér 'амбар', 9. мбара gìrimì 'хижина', в.-чад. 5. бидия gèerà 'дом', gì̀rì 'компаунд', дангла gèr 'компаунд’, мигама gér 'дом', 7. муби gìr 'дом’. Имеется параллель в куш. языках: дараса goo?re, бурджи goore 'хижина, навес'.

c) *gVr- 'деревня, город’: З.-чад. 1 хауса gàrii 'город’; 3. болева gòru id., нгамо gàrgù/u, кирфи gìí, 6. дувай gar gar 'деревня’, ц.-чад. 4. гуде ngúurà ‘большой город’, в.-чад. 7. джегу gére ‘дом, деревня’, зиренкель giri, муби gir, 5. дангла ger 'деревня’.

При наличии такого мощного корня в чадских языках и явной афразийской параллели нужны очень веские аргументы, чтобы доказать заимствование из канури в хауса. Между тем, автор не считает нужным представить для канури хотя бы сахарскую этимологию.

17. Досадные ошибки возникают и из-за игнорирования «внутренней реконструкции» у слова-донора. Например, к числу заимствований из канури отнесено числительное 'три' в языке макари (okuro, ankro). Источником заимствования, по мнению автора, является канури yakkə 'три', yakkero 'трижды' [AlM: 6]. Между тем, из фонетической реконструкции группы котоко, сделанной А. Турно, следует, что -r- в языке макари может восходить как K *-r-, так и к *-n- . В нашем случае как раз и реконструируется чадский корень *kVn-d-22 'три', рефлексы которого хорошо представлены в чадских языках: з.-чад. 1. хауса úkù; 2. герка, чип, монтол, мвагхавул, мупун kún, гоемай kwan, 3. болева *kun(u), 4. * $k V n-d-:$ мия, кария kidi, мбурку kidi, цагу kədə, паа kədu, сири bu-kudi, джимбин kәn-di, 5. зар kan, 6. баде, нгизим kwán, дувай kô; 7. kún; ц.-чад. 1. *ma-kVn-; 2. бура *ma-kVr-, 3. *max-kVn (бана max-kan и т. д.), 4. * mwa-kVn- (бачама ḿmj-kun и т. д.), 5. * $x$-kVr-ḍ- (главда

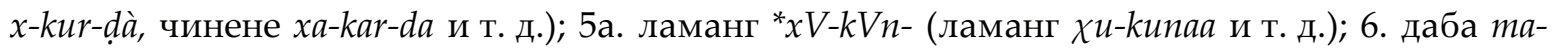
kat (< *ma-kard-), 7. *ma-kan-> ma-kar (мбуко máa-kan, в остальных языках - ma-kar), 7а. сакун máa-kàn, 8. котоко: макари go-kuro, логоне gax-kìr, будума kaa-kénne, 9а. гидар hóokuu, 10. масса *hin-d- < *h-kVn-d- (зиме hindi, hinzizi, и т. д.), в.-чад. 6. мокилко kádùwé (<kand-) ‘в третий раз’ [StD IV №251]. Очевидно, что речь может идти только о заимствовании из чадских языков, причем не только в канури, но и в северные диалекты языка сонгай (тасаваг hin'ze, остальные ka:'rd [Rueck 2001]). В этом случае можно предположить, что числительное заимствовалось в диалекты сонгай из разных чадских языков. Отметим также, что числительное 'три' входило и в список общих корней между чадскими языками и манде (биса karko, само, боаре kaako), составленный Г. Мукаровским для доказательства их генетического родства [Mukarovsky 1995].

18. По фонетическим причинам маловероятно и следующее заимствование: макари $n k i m$ 'пригоршня, open handful' < канури kâm 'горсть, пригоршня' [AlM: 7]. В нилосахарских языках нет эмфатического велярного ${ }^{23}$ (и все старые списки слов это подтверждают). Напротив, в макари (и в родственных языках) эта фонема хорошо сохраняется. В данном случае существует и чадская параллель, а именно: 3.-чад. 4. паа kәтаך, сири

\footnotetext{
22 Тот же суффикс реконструируется в числительных * $m V n$ - $d$ - 'один’ и *fVd-d- ‘четыре'.

${ }^{23}$ См. 'Systèmes alphabétiques d'après Alphabets des langues africains'. Unesco-SIL, 1993.
} 
kan-ta, джимбин kan, мия kəm, мбурку kəmoo, цагу kanə 'arm, hand, рука', 6. нгизим kàmáu 'ощупывать', ц.-чад. 10. зиме kùm 'рукоятка'24 [StD IV №378].

19. Совершенно невозможно и следующее заимствование: макари hàm 'зевать' < канури wásàm id. [AlM: 5]. Сибилянты и сибилянтные аффрикаты хорошо сохраняются в макари (см. таблицу соответствий и многочисленные примеры в [StD III]). Чадские сибилянты $\left({ }^{*}\right.$ s и $\left.{ }^{*} z\right)$ отражаются как $h$ в языке будума, входящем, как и макари, в гр. котоко.

Следует признать, что даже полный чадский материал не всегда помогает решить проблему заимствования, особенно если существует вероятность того, что исконная лексика была утрачена, а затем заимствована из соседних неродственных языков. Такая возможность обосновывается в [JgIb I: 18]. Авторы полагают, что слова для 'лука' и 'стрелы' в в.-чад. языках (5. мигама kéèsè, бидия kè̀se 'лук', 1. кван késē, 3. ндам kēsé, 4 сокоро késé 'стрела') заимствованы из языка багирми (kese 'лук'). Багирми основа, в свою очередь, разумеется, является семитизмом: ср. геэз kast-, арабский kaws-, др.-евр. kä̈̌ät, аккадский kaštu 'лук'. По мнению Д. Коэна, заимствование из семитских языков попало и в кушитский язык билин, а именно: kis-t- 'лук' [Cohen 1969: 128]. Полный чадский материал выглядит следующим образом:

20. ц.-чад. 9. музгу kise 'лук', мбара kèsé 'стрела'; 10. маса kīse 'стрела'; в.-чад. 1. кван késē 'стрела'; 3. тумак keské 'лук', ндам kēsé 'стрела', २àdū-kēsé 'лук’ 25; 4. уби keеsè 'стрела',

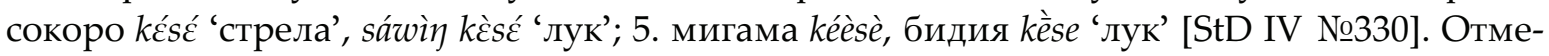
тим следующее: рефлексы в ндам и тумак указывают на *k-, значение 'стрела' превалирует (оно первично для ндам и сокоро, единственное для маса, кван и уби). Оба значения совмещены в музгу (мбара является диалектом музгу), причем можно предположить, что ц.-чад. языки музгу и маса сохранили исходный вокализм первого слова, а в в.-чад. языках произошла ассимиляция гласных. Видимо, мигама и бидия, действительно, могли заимствовать слово для 'лука' из багирми, тем более, что ничего похожего нет ни в одном диалектов дангла², что было бы странно для исконного слова. Рефлексы в остальных языках, напротив, скорее восходят к прачадскому состоянию.

21. Схожую проблему - может ли язык утратить семито-хамитское слово, а затем заимствовать его же заново - приходится решать и в случае с чадской параллелью к общесемитскому *țVlVm- 'быть темным, черным' (арабский, сабейский zlm 'быть темным', геез șalma 'потемнеть, быть темным, черным', тигре șälma, тигринья șällämä 'быть темным', и т. д. [LsG:556]). В чадском это: з.-чад. 3. карекаре с̌àlúm 'тень'; ц.-чад. 2. бура cilim (ci< *çi-/çi-, чад. * či- > бура $\check{c} i-)^{27}$ 'черная земля, используемая как краска'; 8. будума čílim 'черный, темный', гульфей selem 'черный', афаде cálám $\left(c<{ }^{*} c-{ }^{*}{ }^{*}\right.$ - $)$, макари sìlim $\left(s<{ }^{*} c\right.$,

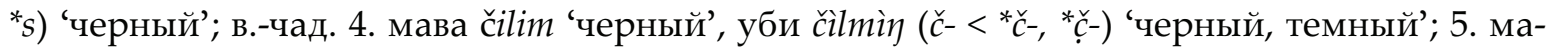
бире čilim 'черный’ [StD III, №974]. Рефлексы в макари и (как ни странно) в будума считаются заимствованиями из канури selem 'черный'. Разумеется, пока не предъявлена нило-сахарская этимология, канури selem можно рассматривать только как заимствование из семито-хамитских языков; возможно - из местного диалекта арабского языка, в котором звонкая аффриката произносится как z- (т. е. zVlVm $>{ }^{*} z V l V m>$ selem). В этом слу-

\footnotetext{
${ }^{24} k<{ }^{*} k,{ }^{*} k$.

${ }^{25}$ В ндам и тумак $k-<* k-$, а $g-<{ }^{*},{ }^{*} g$.

${ }_{26}$ Мигама, бидия и дангла образуют подгруппу внутри в.-чад. ветви.

${ }^{27}$ См. [StD III: 9].
} 
чае гульфей и макари формы могут быть заимствованы из канури (в исконном слове ожидался бы макари ș-). Заметим, однако, что рефлексы в будума и афаде (языки той же группы) никак не могут быть заимствованы из канури.

Заимствованная лексика в чадских языках исследуется фрагментарно и поверхностно. До недавнего времени систематическое исследование не было проведено даже для языка хауса. Задача исправить это положение поставлена авторами проекта 'Заимствования в языке хауса' [AL], осуществляемого в рамках большой программы 'Loanword Typology' [Haspelmath 2008]. К сожалению, несмотря на амбициозные планы руководителей и авторов проекта, основные недостатки всех прежних исследований присущи и ему. Заимствования в хауса из канури, тубу, йоруба и берберских языков анализируются практически вне чадского материала (лишь изредка приводятся кое-какие параллели ${ }^{28}$ ), этимология слова-донора вообще не рассматривается. Кроме того, фонетические соотношения между парами лексем трактуются очень вольно.

22. Например, хауса ità̄̌e 'дерево’ считается почему-то заимствованием из тубу (нило-сахарская семья) idi 'дерево' (статус заимствования: 3. 'perhaps borrowed'). Никаких объяснений фонетическим и структурным несоответствиям не дано. Не приводится и явно родственная лексика из в.-чад. языков: 5. дангла ètò, мигама 2éttú, бидия, 2íto, 7. джегу Reto 'дерево'.

23. Тот же статус имеет и хауса ḅáurée ‘фиговое дерево’ < тубу barke ‘фиговое дерево’. Отметим $b$ - $<b$ - (что хорошо бы прокомментировать). Кроме того, должна была произойти метатеза (-rk->-kr-) и лениция велярного (-kr->-wr- >-ur-). Ввиду того, что кластер -rk- в хауса по частотности едва ли не на первом месте, нет никаких оснований предполагать метатезу в заимствованном слове.

24. Из странных берберских заимствований в хауса отметим: туарегский azar 'жила, веревка из жил' > хауса zàrée 'нить, thread'29. В комментариях даны взаимоисключающие параллели: *sur- 'веревка' (сем.-хам., никакого отношения сюда не имеет) и *z-wr- 'веревка’ (гр. болева, 3.-чад.). К сожалению, релевантная лексика приведена не полностью. Параллель к хауса есть не только в группе болева (карекаре zòorí, гера zùra и др. 'веревка'), но и в других языках: 3.-чад. 7. кулере zàr 'веревка', ц.-чад. 7. мада nzáráwá 'сеть'; 8. макари zari 'сеть', 10. зиме ż̀rà 'силки', в.-чад. 5. дангла zérdé 'крепко связывать' [StD III №546]. Этот чадский корень имеет сем.-хам. этимологию: египетский $z$ ? [zr] 'путы для животного', z’r.w 'путы для лошадей' (сравнение предложено Г. Такачем) и арабский $z w r$ 'привязать животное на длинную веревку (чтобы оно паслось)' [ВК: 1025]. Хотелось бы заметить, что само по себе заимствование zàrée 'нить' из azar 'жила, веревка из жил' не кажется очевидным. Безусловно, необходимо подтвердить на других примерах, что $z$ регулярно заимствуется как $z$, да и семантический переход 'жила' > 'нить' требует комментария. На самом деле, туарегское слово может быть сопоставлено с более близким (и по фонетике, и по семантике) чадским корнем, а именно “çVr- 'strap, bow-string', среди производных которого есть хауса çárkíyáa, çírkíyáa 'тетива' [StD III №783]. Соответствие «туарегский z хауса ç» регулярно; его источником можеть быть любая эмфатическая аффриката (“ç, “产, *⿳⺈).

Разобранные выше примеры позволяют сделать следующие выводы. Вновь возникший интерес к заимствованиям, к сожалению, не стимулировал разработку методики

\footnotetext{
${ }^{28}$ Авторы называют их «historical background».

${ }^{29}$ Не отмечено производное záariya 'веревка, используемая вместо брючного ремня'.
} 
исследования. Все сомнения в оценке степени вероятности заимствования (из-за отсутствия четких критериев) и ошибки, вызванные недостатком сведений о контактирующих языках, характеризуют как работы прошлых лет, так и современные проекты. Основным же критерием так и остается высокий социальный статус языка-донора. Следует признать, что при исследовании заимствований на материале бесписьменных языков в поле зрения должны находиться максимально полные лексические базы данных и этимологии обоих слов, а также сведения об исторической фонетике. Иначе говоря, работы такого рода должны вестись в рамках проектов, включающих специалистов по сравнительному изучению как одной, так и другой семьи языков. В противном случае оценка вероятности заимствования всегда будет колебаться между ‘возможно’ и 'маловероятно’.

\section{Сведения о классификации чадских языков:}

западная ветвь: 1 язык хауса, 2 сура, 3 болева, 4 варджи, 5 зар, 6 нгизим, 7 рон; цุентральная ветвъ: 1 тера, 2 бура, 3 хиги, 4 бата, 5 матакам, 5а ламанг; 6 даба, 7 мафа, 7а язык сакун, 8 котоко, 9 музгу, 9а язык гидар, 10 маса;

восточная ветвъ: 1 кера, 2 леле, 3 сомрай, 4 сокоро, 5 дангла, 6 язык мокилко, 7 муби.

\section{Сокращения}

в. - восточный, гр. - группа, диал. - диалект, др.-евр. - древнееврейский, ег. - египетский, з. - западный, куш. - кушитский, сем.-хам. - семито-хамитский, ц. - центральный, чад. - чадский.

\section{Дитература ${ }^{30}$}

Поздняков 1993 - Поздняков, К. И. Сравнительная грамматика атлантических языков. Восточная литератуpa, M., 1993. [POZDNYAKOV, K. I. Sravnitel'naya grammatika atlanticheskih yazykov. Vostochnaya literatura, M., 1993.]

AL - AwaganA, Ari \& Doris LöHR. Loanwords in Hausa. In: Topics in Chadic Linguistics 5. Rüdiger Köppe Verlag, Köln, 2009, pp. 37-51.

AlM - AlisOn, Sean. Lexical Evidence for the Islamization of the Marari Kotoko by Kanuri, unpubl.

Appleyard 2006 - APPlEYARD, David L. A Comparative Dictionary of the Agaw languages. Rüdiger Köppe Verlag, Köln, 2006.

Baldi 1995 - BALDI, Sergio. On Arabic loans in Hausa and Kanuri. In: Ibriszimow, D. \& R. Leger (eds.) Studia Chadica et Hamito-Semitica. Rüdiger Köppe Verlag, Köln, 1995, pp. 252-278.

BK - Biberstein-KAZIMIRSKY, A. de. Dictionnaire arabe-français. 2 vol. Naisonneuve et Cie. Paris. 1960.

Cohen 1969 - COHEN, David. Dictionnaire des racines sémitiques. Paris, 1969.

Greenberg 1947 - GreEnBERG, J. H. Arabic Loan-Words in Hausa. In: Word 3, 1947, pp. 85-97.

Haspelmath 2008 - HASPELMATH, Martin, Loanword typology. Steps toward a systematic cross-linguistic study of lexical borrowability. In: STOLZ, T. (ed.). Aspects of language contact. Mouton, Berlin 2008, pp. 43-62.

JgIb - Jungraithmayr, Herrmann and Dymitr IbRIszimow. Chadic Lexical Roots. 2 vol. Reimer Verlag, Berlin, 1994.

Kogan 2003 - KogAn, Leonid, Popular Etymology in the Semitic Languages. In: Studia Semitica, Moscow, 2003, pp. $120-140$.

Kölle 1854 - S. W. KÖLle. Polyglotta Africana. Church Missionary Society. London, 1854.

LsG - LeSLAU, Wolf. Comparative Dictionary of Ge'ez. Harrassowitz, Wiesbaden. 1986.

Mukarovsky 1995 - MuKArovsKy, H. Chadic, Mande, Nigritic. In: IBrisziMOW, D. \& R. Leger (eds.) Studia Chadica et Hamito-Semitica. Rüdiger Köppe, Köln, 1995, pp. 65-76.

\footnotetext{
${ }^{30}$ Полную библиографию по чадским языкам см. в [StD IV , стр. 12-19].
} 
Rueck 2001 - RUECK, Michael and Niels CHRISTIANSEN. Northern Songay Languages in Mali and Niger. SIL, 2001.

Reinisch 1895 - REINISCH, Leo. Wörterbuch der Bedauye-Sprache. A. Hölder, Wien, 1895.

Sasse 1978 - SASSE, Hans J. The Consonant Phonemes of Proto-East-Cushitic. Afroasiatic Linguistics, 7 (1), 1978.

Schuh 2003 - SCHUH, Russel. The linguistic influence of Kanuri on Bade and Ngizim, 2003: www.africanlanguages. org.

Schuh 1981 - ScHUH, Russel. Dictionary of Ngizim. University of California Press, Berkeley \& Los Angeles. 1981.

SkH - SKINNER, Neil. Hausa Comparative Dictionary. Rüdiger Köppe Verlag. Köln, 1996.

StD I-IV - StOlbovA, Olga, Chadic Lexical Database. Isssues I-IV / Пексическал база данных по чадским языкам. Полиграфия, Москва-Калуга, 2005-2011.

Williamson 1973 - WiLliamson, K., SHIMIZU, K. (eds.). Benue-Congo comparative Wordlists. Ibadan, 1973.

Zarma 2001 - Zarma Dictionary. Prepareed by Peace Corps, Niger, 2001: http://www.bisharat.net/Zarma/

The Chadic branch of the Hamito-Semitic (Afrasian) macrofamily includes about 150 unwritten languages of Nigeria and Cameroun. Over the course of the past 4,000-6,000 years Chadic languages have been exposed to influence from various Nilo-Saharan and NigerCongo languages, which resulted in a great degree of linguistic interlacing. The linguistic influence of dominant languages (Kanuri, Bagirmi, Fulfulde, etc.) on Chadic ones is generally recognized as responsible for the typical direction of borrowings: from donor languages into Chadic. The present paper takes into consideration some of the most characteristic mistakes that result from this approach. In order to identify loanwords, it is suggested, on one hand, that a proper etymology of the hypothetical source word be presented; on the other hand, one should also be sure that the hypothetical loanword has no etymology of its own (or 'historical background', as it is called in the «Loanword Typology Project»). In other words, research on historical phonology and lexicon within the framework of both families should precede the identification of borrowings.

Keywords: Chadic languages, Africa, Nilo-Saharan languages, Niger-Congo languages, loanwords, borrowing, etymology, lexicon, phonology. 
